DOI: https://doi.org/10.15688/re.volsu.2019.1.6

UDC 338.2

Submitted: 03.01.2019

LBC 65.050

Accepted: 01.02.2019

\title{
THE ROLE OF NETWORK COMMUNITIES IN THE STRATEGIC DEVELOPMENT OF CITIES AND REGIONS
}

\author{
Vyacheslav G. Maracha \\ Russian Presidential Academy of National Economy and Public Administration, Moscow, Russian Federation; \\ Financial University under the Government of the Russian Federation, Moscow, Russian Federation
}

\section{Tatyana S. Krasnikova}

\author{
Scientific Research LLC, Moscow, Russian Federation
}

\begin{abstract}
In this paper we discuss the impact of modern transformation of the economy and the society on the processes of strategic planning on the basis of network interaction. We define the notion of network communities and highlight the opportunities and problems of interaction between government and these communities in the process of strategizing. As one of the manifestations of the global trend of "networkization" of the economy and society, the transition to cluster interaction based on regional collaborative communities and the model of "Cluster Governance" are considered. Ideal models of public administration for the state and municipal government are considered in the context of the challenges of "networkization", which allows us to trace and justify the evolution of public administration. There is a connection between the issues of organizing stakeholder communication and public participation in the strategy process with a change in public administration model. A typology of network communities in the context of the problem of organizing communication of stakeholders and public participation in the process of cities and regions strategizing is proposed. The various formats of communication and collaboration with network communities in the process of cities and regions strategizing, as well as prospects for using digitalization tools in this communication are considered.
\end{abstract}

Key words: network communities, strategic development of cities and regions, strategic planning process, stakeholders, public participation, public communication, dialogue model of discussion.

Citation. Maracha V.G., Krasnikova T.S. The Role of Network Communities in the Strategic Development of Cities and Regions. Regionalnaya ekonomika. Yug Rossii [Regional Economy. The South of Russia], 2019, vol. 7, no. 1, pp. 66-78. (in Russian). DOI: https://doi.org/10.15688/re.volsu.2019.1.6

\section{РОЛЬ СЕТЕВЫХ СООБЩЕСТВ В СТРАТЕГИЧЕСКОМ РАЗВИТИИ ГОРОДОВ И РЕГИОНОВ}

\author{
Вячеслав Геннадиевич Марача \\ Российская академия народного хозяйства и государственной службы при Президенте РФ, \\ г. Москва, Российская Федерация; \\ Финансовый университет при Правительстве РФ, г. Москва, Российская Федерация
}

Татьяна Сергеевна Красникова

ООО «Научные разработки», г. Москва, Российская Федерация

\begin{abstract}
Аннотация. В статье рассматривается влияние современной трансформации экономики и общества на основе сетевого взаимодействия на процессы стратегического планирования, дается определение сетевых сообществ и выде-
\end{abstract}

(C) Марача В.Г., Красникова Т.С., 2019 
ляются возможности и проблемы взаимодействия органов власти с данными сообществами в процессе стратегирования. В качестве одного из проявлений глобального тренда «сетевизации» экономики и общества проанализирован переход к кластерному взаимодействию, опирающемуся на региональные коллаборативные сообщества, и к модели «кластерной организации управления» (Cluster Governance). Идеальные модели государственного и муниципального управления рассматриваются в контексте вызовов «сетевизации», что позволяет проследить и обосновать эволюцию государственного и муниципального управления. Прослеживается связь вопросов организации коммуникации стейкхолдеров и общественного участия в процессе стратегирования с изменением модели государственного и муниципального управления. Предложена типология сетевых сообществ в контексте проблемы организации коммуникации стейкхолдеров и общественного участия в процессе стратегирования городов и регионов. Рассмотрены различные форматы коммуникации и совместной работы с сетевыми сообществами в процессе стратегирования городов и регионов, а также перспективы использования инструментов цифровизации в данной коммуникации.

Ключевые слова: сетевые сообщества, стратегическое развитие городов и регионов, процесс стратегического планирования, стейкхолдеры, общественное участие, общественная коммуникация, диалоговая модель обсуждения.

Цитирование. Марача В. Г., Красникова Т. С. Роль сетевых сообществ в стратегическом развитии городов и регионов // Региональная экономика. Юг России. 2019. Т. 7, № 1. С. 66-78. DOI: https://doi.org/10.15688/re.volsu.2019.1.6

\section{Введение}

23 октября 2018 г. в Санкт-Петербурге в рамках XVII Общероссийского форума «Стратегическое планирование в регионах и городах России» (далее - «Форум стратегов») прошла дискуссионная панель «Сетевые сообщества как акторы социальных инноваций и стейкхолдеры стратегического развития городов», в число организаторов которой входили и авторы данной статьи. Стенограмма дискуссионной панели будет опубликована, а в данной работе представляется наш собственный взгляд на обсуждаемую проблематику.

Во избежание путаницы сразу отметим, что под сетевыми сообществами мы будем понимать любые сообщества (communities), взаимодействие участников которых построено в соответствии с принципами сетевой организации. При этом не важно, откуда берутся технологии и инструменты сетевой организации: они могут как вырабатываться самим сообществом (это случай самоорганизации, рассмотренный ниже на примере Cluster Governance), так и заимствоваться извне (например, в социальных сетях). В качестве стейкхолдеров далее рассматриваются не любые «заинтересованные стороны» (такой перевод данного термина закрепился в отечественной литературе), а те, которые способны реально влиять на принятие решений. Поскольку речь идет о стратегическом развитии, то в данном контексте мы считаем правомерной трактовку стейкхолдеров как «стратегических субъектов» развития.

\section{Основные вызовы «сетевизации» экономики и общества}

Один из глобальных трендов современности состоит в том, что экономика и общество трансформируются на основе сетевого взаимодействия с доминированием горизонтальных связей [Кастельс, 2000; Смородинская, 2014]. Основные вызовы «сетевизации» заключаются в том, что в ключевых отраслях экономики и социальной сферы, в государственном и муниципальном управлении системы, основанные на доминировании иерархических отношений, постепенно становятся неконкурентоспособными. Им на смену приходят совершенно новые способы организации и самоорганизации: формируются инновационные кластеры [Porter, 1998; van den Berg, Braun, Winden, 2001] и экосистемы [Смородинская, 2014], появляется «шеринговый» тип экономики.

Сетевое взаимодействие становится условием формирования коллабораций и инновационных сред во всех вышеупомянутых сферах. В экономике гигантские корпорации, построенные по иерархическому принципу, уже не дают прежней «экономии на масштабе», поскольку ключевым фактором конкурентоспособности становится гибкость, способность понимать своего клиента и удовлетворять его потребности. Большие конвейеры, традиционная кооперация и методы разработки новых продуктов уступают место agile-подходам и работе «под заказ», а маркетинговое манипулирование потребностями клиентов теперь должно учитывать тот факт, что сами клиенты объединяются в сетевые сообщества, по сути осуществляющие всестороннюю экспертизу потребительских качеств товаров и услуг. Это охлаждает псевдоинновационный пыл производителей, навязывающих потребителям приобретение новой продукции под предлогом «морального устаревания» прежней или изменения моды. Потребители, объединенные в сетевое сообщество, 
становятся более критичны к обещаниям рекламы, поскольку на практике «устаревшая» продукция зачастую оказывается более качественной и надежной, а постепенное формирование «шерингового» типа экономики и вовсе представляет собой альтернативу идеологии «общества потребления».

Одной из важнейших для современной экономики форм сетевой организации инновационного процесса стали инновационные кластеры, в основе которых лежат региональные коллаборативные сообщества [Smorodinskaya et al., 2017; Gloor, 2006; Camarinha-Matos, Afsarmanesh, 2008; Nieto, Santamaría, 2007; Bramwell, Hepburn, Wolfe, 2012]. Американские исследователи Энн Томсон и Джеймс Перри определяют коллаборацию (collaboration) как процесс формальных и неформальных согласований между автономными игроками, в ходе которого они создают совместные правила и организации для регулирования своих взаимодействий и направлений деятельности или решают объединяющие их задачи [Thomson, Perry, 2006]. Эти согласования могут происходить непрерывно, а совместные правила должны разделяться всеми участниками, обеспечивая их синергию. По мнению Н.В. Смородинской, понятие «коллаборация» происходит от слова «лаборатория», отражая характер взаимоотношений, некогда сложившихся в лабораториях американской Кремниевой долины, которые дали миру образец высшей, интерактивной формы кооперации [Смородинская, 2014, с. 28].

В рамках модели «кластерной организации управления» (Cluster Governance) [Gilsing, 2000; Марача, Красникова, 2017] кластерное взаимодействие рассматривается нами как разновидность сетевой коллаборации. Специфика кластерной сети состоит в том, что один из ее «узлов» принимает на себя роль «ядра», выполняющего координирующие и инфраструктурные функции. В контексте осуществления этих функций отношения между координирующим «ядром» и участниками кластера приобретают «вертикальный» характер, но, в отличие от традиционной внутрифирменной иерархии, в кластере они основаны не на принуждении, а на добровольном делегировании «ядру» части «суверенитета» участников. При этом все прочие отношения между участниками кластера остаются рыночными, а связи горизонтальными. Тем самым в рамках модели Cluster Governance соединяются преимущества иерархической и рыночной форм организации [Марача, Красникова, 2017].
Из плюралистичности и гетерогенности состава кластера вытекает коммуникативный характер взаимодействия внутри него. Одной из ключевых характеристик кластерной сети, определяющей синергетический эффект кластеров, является «неформальный обмен информацией, знаниями и креативными идеями» [van den Berg, Braun, van Winden, 2001; Breznik, 2016; Turkina, Assche, Kali, 2016; He, 2016; Desrochers, 2001; Kemeny et al., 2016, Farré-Perdiguer, Sala-Rios, Torres-Solé, 2016]. Для кластера как регионального коллаборативного сообщества такой обмен облегчается территориальной концентрацией участников сети, а в случае инновационной экосистемы обмен интенсифицируется за счет мобильности участников и применения современных информационных технологий, поддерживающих «технологическую платформу» экосистемы. Этот обмен осуществляется через прямую коммуникацию, которая, как показывают эмпирические исследования, должна проникать на уровень среднего менеджмента и ключевых специалистов организаций-участников [Марача, Красникова, 2017]. Соответственно, и кластерное управление должно иметь характер коммуникативного управления.

Смена парадигмы управления, привносимая сетевой организацией, затрагивает не только экономику, но и социальную сферу, общественные пространства, взаимодействие власти и граждан. Сетевые сообщества становятся новыми акторами в социальном пространстве: они меняют преобладающие социально-экономические практики, задают требования к инфраструктуре и городской среде, к предметной направленности и «адресности» городских и региональных программ.

Проблема участия сетевых сообществ в определении будущего территории, на которой они живут, особенно актуальна в городах, где и социальные связи, и предметная среда отличаются наивысшей плотностью, а эффекты взаимозависимости человеческой деятельности и среды во всех смыслах этого слова проявляются наиболее ярко. Остроту данной проблематики в современных городах можно продемонстрировать на примере развития социальной инфраструктуры.

В силу самой природы социальной инфраструктуры в ее развитии большую (а часто ключевую) роль играют государственные и муниципальные власти. При этом отечественная система государственного и муниципального управления сформировалась в рамках индустриаль- 
ного общества, где социальная инфраструктура рассматривается как система массового социального обслуживания, которая обеспечивает условия воспроизводства рабочей силы, поставляя весь необходимый для этого набор «благ»от продовольственных и промышленных товаров до образования, охраны здоровья и поддержания культурно-нравственного потенциала работников, их детей и пенсионеров. Такая система, как правило, создается государством и входит в сферу его ответственности, для осуществления которой разрабатывается нормативная модель среднестатистического, «усредненного» потребителя. Это позволяет ввести единую систему нормативных показателей удовлетворения потребностей в объектах социальной инфраструктуры, которая используется при их проектировании, эксплуатации и управлении соответствующими городскими процессами.

Однако в современном обществе социальная инфраструктура начинает использоваться в принципиально иной парадигме - не системы массового социального обслуживания, а «социальных услуг» как части «экономики услуг», характерной для постиндустриального общества. Анализ роли и значения сферы услуг в структуре современной экономики развитых стран показывает тенденции увеличения доли занятых и доли доходов от сферы услуг в ВВП (рост доли «экономики услуг»), что можно трактовать как одно из свидетельств перехода к постиндустриальному этапу развития. С начала 2000-х гг. данная тенденция в полной мере проявилась и в России.

Современным культурно-историческим трендом изменения поведенческих ориентаций населения по отношению к услугам социальной инфраструктуры является завершение перехода от доиндустриального уклада к индустриальному и переход от индустриального уклада к постиндустриальному. При этом постиндустриальное общество характеризуется переходом не только к «экономике услуг», но и к «экономике, основанной на знаниях», где основным предназначением социальной инфраструктуры становится поддержание процессов воспроизводства и развития «человеческого потенциала» территории.

Переходный характер ситуации, в которой находится общество, порождает многоукладность поведенческих предпочтений населения в объектах социальной инфраструктуры, выражающуюся в разнообразии «образов жизни». Соответственно, при градостроительном проектиро- вании объектов социальной инфраструктуры мы уже не можем использовать единую систему нормативных показателей, ориентированную на некоего среднестатистического, «усредненного» потребителя. Актуальным становится учет разнообразия потребительского поведения и соответствующего различия потребностей в объектах и услугах социальной инфраструктуры в зависимости от образа жизни и иных характеристик потребителя.

В тех случаях, когда можно говорить о формировании рынка социальных услуг (это возможно в том числе и на базе одних и тех же объектов социальной инфраструктуры), учет разнообразия потребностей осуществляется на основе исследований потребительского поведения. Однако, несмотря на то что подобные исследования позволяют достаточно успешно решать задачи развития рынка услуг, при применении соответствующих подходов и моделей необходимо иметь в виду, что они основываются на парадигме индивидуального рационального выбора, которая не учитывает природу социальной инфраструктуры как рыночного и, прежде всего, общественного блага. В этом проявляется методологическая ограниченность исследований потребительского поведения в контексте решения задач градостроительного проектирования социальной инфраструктуры.

Проведение исследований потребительского поведения само по себе никак не гарантирует устранения проблемы исторического отчуждения простых горожан от решения общественно значимых вопросов развития города. Важную роль играет то, в рамках какой из моделей государственного и муниципального управления используются результаты подобных исследований.

\section{Три идеальные модели государственного и муниципального управления и его эволюция в контексте вызовов «сетевизации»}

Для классификации идеально-типических моделей государственного и муниципального управления в данной работе использована типология, основанная на теоретико-организационном различении доминирующих структур отношений «иерархии - рынки - сети» [Бевир, 2015]. Сетевым формам здесь соответствует «общественно-сетевая» модель New Governance, которая в развитых станах накладывается на классическую «веберианскую» модель рациональной бю- 
рократии (иерархии) [Weber, 2015; Wilson, 1887] и дополняющую ее рыночно ориентированную модель New Public Management [Казакова, Поспелова, 2014] (см. таблицу).

Три перечисленные модели различаются системными принципами управления, реализуемыми в проблемных контекстах, различающихся по типу системной зависимости их участников (см. второй столбец таблицы; данная типология проблемных контекстов введена известным британским специалистом по системному мышлению М. Джексоном [Jackson, 2003]). Это подчеркивается использованием разных англоязычных терминов: Control \& Administration (управление, реализуемое в иерархических структурах с «жесткой» зависимостью участников), Management (соответствует рыночно ориентированной модели «мягких» систем, формально независимые участники которых могут свободно договариваться) и Governance (соответствует общественно-сетевой модели «коэрцитивных» систем со взаимозависимыми участниками).

Рассмотренные выше вызовы «сетевизации» экономики и общества погружают нас в проблемные контексты, соответствующие третьей строке таблицы, что требует адекватного ответа в виде реформ государственного и муниципального управления. Однако в нашей стране элементы модели New Governance (участие и партнерство, основанное на диалоге стейкхолдеров) внедряются крайне слабо ввиду понятных политических и гораздо реже анализируемых, но более фундаментальных социокультурных ограничений (в целом об этом можно говорить как об институциональных ограничениях, понимая институты как комплексные социокультурные образования, то есть шире, чем это при- нято в неоинституциональной теории). Социокультурные ограничения препятствуют институциональным реформам, позволяющим перейти к более продвинутым моделям государственного управления [Социокультурные факторы ... , 2017], а это, в свою очередь, тормозит инновационное развитие, и в частности формирование инновационных кластеров и экосистем. Государственное стимулирование в силу неадекватности устаревших типов управления оказывается неэффективно, а переход к кластерной организации управления «естественным путем» затруднен ввиду тех же социокультурных ограничений: вертикально-интегрированные холдинги для российских управленцев гораздо понятнее и «культурно ближе», чем «неуправляемые» кластеры и экосистемы.

Аналогичным образом запаздывание реформ государственного и муниципального управления препятствует адекватному ответу на вызовы «сетевизации» и в других областях, где требуется переход к новой парадигме управления. Так, опираясь на типологию, представленную в таблице, довольно легко убедиться, что, хотя социологические исследования проводились и в советское время, это не меняло иерархического характера отношений между городскими властями и горожанами: власти принимали результаты исследований «к сведению», но решали все равно по-своему. И если благодаря постиндустриальному развитию рынков коммерческих услуг в ряде сфер отношения горожан и поставщиков этих услуг из вертикально-иерархических превратились в горизонтально-рыночные (договорные), то применительно к услугам социальной инфраструктуры в значительной степени сохраняется ее трактовка как системы массового социального обслуживания и прежняя система управления. Эта система управления построена на иерархии и «вменении» горожанам на-

Таблийа

\section{Соответствие между типами организации / управления и моделями государственного / муниципального управления}

\begin{tabular}{|l|l|l|l|}
\hline $\begin{array}{l}\text { Тип организации / } \\
\text { управления }\end{array}$ & $\begin{array}{c}\text { Тип системной зависимости } \\
\text { участников }\end{array}$ & $\begin{array}{c}\text { Модель государственного / } \\
\text { муниципального управления }\end{array}$ & $\begin{array}{c}\text { Фокусировка } \\
\text { модели }\end{array}$ \\
\hline $\begin{array}{l}\text { Иерархическая / } \\
\text { Control \& } \\
\text { Administration }\end{array}$ & $\begin{array}{l}\text { Нагd - «жесткая» зависимость } \\
\text { участников }\end{array}$ & Рациональная бюрократия & На процедуре \\
\hline $\begin{array}{l}\text { Рыночная / } \\
\text { Маnagement }\end{array}$ & $\begin{array}{l}\text { Soft - формальная независи- } \\
\text { мость участников, которые мо- } \\
\text { гут свободно договариваться }\end{array}$ & New Public Management (NPM) & На результате \\
\hline $\begin{array}{l}\text { Ceтевая / } \\
\text { Governance }\end{array}$ & $\begin{array}{l}\text { Сoersive - взаимозависимость } \\
\text { участников }\end{array}$ & New Governance & $\begin{array}{l}\text { На участии и } \\
\text { партнерстве }\end{array}$ \\
\hline
\end{tabular}

Примечание. Составлено авторами ${ }^{1}$. 
бора услуг, обладающих общественным благом по мнению городских властей. По сути, городские власти управляют социальной инфраструктурой как собственной «естественной монополией», от которой зависят все горожане (и для которых выбор «рыночной» альтернативы не всегда возможен), но доступ к принятию решений есть только у властей.

Альтернативой «вертикальным» (иерархическим) и «горизонтальным» (рыночным / договорным) структурам являются общественно-сетевые, основанные на общественном участии [Hartay, 2011; King, Stivers, 1998; Nelson, Wright, 1995; Oldfield, 1990; Standards of Public Participation ..., 2008] в выработке градостроительных решений. Особенно ярко это проявляется в практиках современного урбанизма, связанных с «соучаствующим проектированием» (participative design), которое представляет собой совокупность методов и форматов вовлечения местных сообществ и иных стейкхолдеров в разработку и реализацию градостроительных проектов и решений, основанную на принципах партисипативности. Соучаствующее проектирование является одной из практик общественного участия (public participation) [Arnstein, 1969], то есть участия представителей местных сообществ и иных стейкхолдеров в выработке, принятии, реализации и оценке общественно значимых решений и подготовке соответствующих документов.

\section{От стратегического планирования к стратегированию: необходимость коммуникации стейкхолдеров и общественного участия}

Ответы на стратегические вызовы призвана давать не только общественная практика, но и законодательство, задающее правовые нормы, которые регламентируют реализуемые в ходе этой практики отношения ее участников. Так, например, статья 13 Федерального закона от 28.06.2014 г. № 172-ФЗ «О стратегическом планировании в Российской Федерации» [Федеральный закон от 28.06.2014 № 172-Ф3] предписывает выносить проекты документов стратегического планирования на общественное обсуждение. Однако характер практической реализации данной нормы закона в нашей стране не устраивает ни общественность, ни органы государственной власти. Представители первой критикуют формальный характер общественных обсуждений, а вторые указывают на неконструктивный характер таких обсуждений.
Как было показано в нашей предшествующей работе [Красникова, Марача, 2018], сформированный в России институт общественных обсуждений проектов документов стратегического планирования не обеспечивает должное повышение качества процесса стратегирования. Этому препятствуют две группы проблем, которые глубоко взаимосвязаны: 1) проблемы, обусловленные низким качеством организации общественной вовлеченности в процесс стратегирования; 2) проблемы, обусловленные имитационным, формальнодекларативным характером общественного участия в данном процессе.

На основе анализа опыта ряда российских регионов было показано, что основная причина невысокой активности и качества общественного обсуждения - низкий уровень доверия как общественности, так и органов власти к существующим институтам общественного участия, подпитываемый неготовностью органов государственной и муниципальной власти к горизонтальной (коммуникационной, диалоговой) модели обсуждения. Важно, чтобы произошел переход от «вертикального» к «горизонтальному» стилю коммуникации представителей органов государственной и муниципальной власти с общественностью, то есть от «разговора с позиции силы» (в уведомительном порядке, в порядке информирования о выработанном решении и т. п.) к содержательному обоснованию и взаимодействию, опирающемуся на стремление к согласованию стратегических целей и приоритетов.

Почему же, несмотря на наличие хорошо описанного опыта развитых стран, такой переход не происходит или осуществляется с большой задержкой? Одной из причин является упомянутое выше запаздывание реформ государственного и муниципального управления, приводящее к тому, что процесс стратегического планирования «втискивается» в прокрустово ложе устаревшей системы управления, в которой под видом новизны выдается заимствование опыта крупных корпораций в рамках модели New Public Management (вторая строка таблицы), сфокусированной на результате, а не на участии и партнерстве, как требует общественно-сетевая модель New Governance. И то, что в крупных корпорациях было нормальным разделением труда между топ-менеджментом (блок стратегического управления) и всеми остальными (операционный менеджмент и исполнители), в государственном и муниципальном управлении превратилось в «разделение труда» между стратегическим пла- 
нированием и реализацией стратегий, что в конечном счете означает разрыв между властью и гражданами.

В этом случае сам процесс стратегического планирования осуществляется властью, а гражданам достается лишь исполнение разработанного властью «плана». И если власть хочет вовлечь общественность в стратегическое планирование, то имеется в виду их участие не в процессе планирования, а только в обсуждении его результатов в виде стратегических документов, уже разработанных до высокой степени готовности. И тогда внесение изменений уже проблематично, а институт общественного обсуждения теряет тот смысл, ради которого он создан. При этом с гражданами не обсуждается ни концептуальная основа стратегических документов, ни различные сценарии развития (имеющие «развилки» и альтернативы), ни выбор приоритетов (требующий обоснования).

Если же государственное и муниципальное управление переходит к общественно-сетевой модели New Governance, которая сфокусирована на общественном участии и партнерстве с гражданами, а не только на результатах, необходим принципиально иной подход и к стратегическому планированию. Анализ лучших мировых и отечественных практик показывает, что в этом случае происходит переход от стратегического планирования в описанном выше смысле к стратегированию, под которым понимается расширение стратегического планирования до полного «стратегического цикла», представляющего собой управленческий цикл Деминга - Шухарта PDSA, перенесенный на стратегический уровень управления и включающий четыре фазы ${ }^{2}$ : 1) стратегический анализ ситуации и планирование; 2) принятие стратегических решений (определение приоритетов и политики, нормотворчество); 3) «имплементация» - реализация политики и стратегических мероприятий, применение норм; 4) контроль, оценка и коррекция (осуществление обратной связи на основе контроля и оценки с последующим переходом к следующему шагу «цикла»).

В каждой фазе происходит содержательная коммуникация органов государственной и муниципальной власти со стейкхолдерами, позволяющая выявить общие предметы обсуждения для участников данного диалога, объективно выступающих в качестве партнеров в поле региональной политики, и обосновать взаимное пересечение их интересов. При этом стратегический анализ ситуации начинается с оценки успехов и не- удач предыдущих планов, изучения причин их невыполнения. Вовлечение общественности в процесс стратегического планирования подразумевает участие стейкхолдеров в обсуждении концепции стратегического документа, альтернативных сценариев и «развилок». Принимая стратегические решения, власть обосновывает определение приоритетов и политики, вовлекает стейкхолдеров в процесс нормотворчества (через процедуры оценки регулирующего воздействия, рассмотрение законопроектов в общественных палатах, открытые парламентские слушания и другие институты общественного участия). А общественное участие в «имплементации» стратегии обеспечивает затем эффективное осуществление обратной связи через процедуры контроля реализации стратегических мероприятий и достижения показателей, оценку результатов и возможность предложить корректирующие меры. Все вышеперечисленное позволяет в ходе горизонтального взаимодействия и многопозиционной коммуникации на каждой фазе «стратегического цикла» не просто найти стратегические решения, приемлемые для всех участников диалога, но и обеспечить синергетический эффект их совместных усилий при реализации данного решения.

\section{Основные типы сетевых сообществ в контексте проблемы организации коммуникации стейкхолдеров и общественного участия в процессе стратегирования городов и регионов}

Как мировая, так и российская практика свидетельствуют, что органы власти различных уровней далеко не всегда выступают сторонниками институциональных трансформаций. Чаще они, наоборот, заинтересованы в консервации устаревших моделей государственного управления. Даже когда представители власти выдвигают передовые лозунги и позиционируют себя как сторонники всего нового и прогрессивного, на практике им бывает довольно сложно отойти от привычных иерархических структур управления (то есть от типа управления, который выше был обозначен как Control \& Administration), сменив их на общественно-сетевые. Это требует перехода от иерархических отношений «начальник подчиненный» к «горизонтальной» коммуникации профессионалов в различных областях, а также к партнерским отношениям власти и общества, которое в рамках общественно-сетевой модели представлено в виде сетевых сообществ. 
Поскольку проблематика городского и регионального стратегирования связана с будущим развитием территорий, интересующая нас типология сетевых сообществ может строиться по аналогии с различием инновационных кластеров и экосистем: первый тип будет соответствовать территориальным сетевым сообществам, второй - экстерриториальным. Попробуем ответить на вопрос: какие из них могут быть стейкхолдерами развития городов и регионов?

Заинтересованность сообществ первого типа в развитии территорий понятна, ведь они сами локализованы и развитие территории влияет и на их будущее. Правда, здесь придется различить те сообщества, которые являются территориальными только по названию (например, «клуб филателистов города $\mathrm{N»),} \mathrm{и} \mathrm{те,} \mathrm{ко-}$ торые являются подлинными патриотами своей «малой родины». Но если мы оцениваем сетевые сообщества по «степени подлинности» их интереса к территории, то и стейкхолдеров необходимо делить на «реальных» и «номинальных» (так же, как «реальными» и «номинальными» бывают держатели акций - shareholders). И тогда можно предположить, что реальными стейкхолдерами стратегического развития городов и регионов могут быть не только территориальные, но и экстерриториальные сетевые сообщества (профессиональные, экспертные, научные, инновационные и т. д.).

Соответственно, перед заказчиками стратегий и модераторами процессов стратегирования возникает вопрос о выборе адекватных партнеров по коммуникации. Данный вопрос подробно обсуждался на упомянутой выше дискуссионной панели «Форума стратегов» в Санкт-Петербурге, где было показано, что процесс стратегирования осложняется проблемой «удобных» для власти и «имитационных» сообществ. В частности, Александр Сунгуров привел пример того, как в ходе борьбы горожан против строительства офиса Газпрома в устье Охты были проведены общественные слушания. Большинство их участников это строительство однозначно поддержало. Потом журналисты стали спрашивать участников: «Откуда вы?» - «Мы, - говорят, - из массовки Ленфильма. Нам, как всегда, по пятьсот рублей заплатили, мы пришли и проголосовали, как им надо».

В международной терминологии есть две звучных аббревиатуры для обозначения негосударственных организаций, маскирующихся под представительство общественных интересов, но на деле защищающих совсем другие: $\mathrm{GANGO}^{3}$ и $\mathrm{MANGO}^{4}$. А противоположностью их являются те, кому «не все равно», или, как в советское время говорили, «неудовлетворенцы», то есть те, кто неудовлетворен существующим положением дел и переживает за общественные интересы. Именно они и являются источником общественного развития.

С другой стороны, среди независимых и инициативных общественников всегда найдутся люди «с отклонениями в психике», но они такие же граждане, и их тоже надо выслушать. Однако при этом необходимо отделить позиции, реально выражающие общественные интересы, от идей «городских сумасшедших».

Таким образом, в выборе партнеров по коммуникации в процессе стратегирования есть два ограничения. С одной стороны, нужно отсечь «городских сумасшедших» и представителей интересов «мафии», а с другой стороны, нельзя ограничиваться только теми общественными объединениями, которые комфортны для власти и заведомо разделяют ее позицию.

\section{Различные форматы коммуникации и совместной работы \\ с сетевыми сообществами в процессе стратегирования городов и регионов: их преимущества и возможности сочетания}

Для успешного вовлечения сетевых сообществ в процессе стратегирования городов и регионов нужно выбрать не только адекватных партнеров по коммуникации, ограничив влияние «удобных» и «имитационных» сообществ, но и определить наиболее работоспособные и эффективные форматы коммуникации и совместной работы с учетом их преимуществ и возможностей сочетания. В качестве инструмента решения данной задачи можно использовать две классификации.

1. Классификация форм организации коммуникации между стейкхолдерами [Марача, 2008, c. 41]: а) немодерируемые традиционные формы (переговоры, совещания, согласительные комиссии и т. д.); б) модерируемые событийные формы (семинары, круглые столы, дискуссионные панели, различные форумы и т. д.); в) модерируемые процессные формы (тематические, проектные и иные рабочие группы, форсайт, организационно-деятельностные игры и производные от них формы, включая стратегические сессии, а также общественные экспертизы, в том числе 
профессионально-общественные, методологически организованные, проводимые в формате «жюри граждан» и т. п.).

Положительной чертой традиционных форм является простота, а модерируемых - возможность организации диалога между различными позициями там, где он не получается «естественным» путем. Выбор между событийными и процессными формами организации коммуникации определяется характером решаемых задач, наличием времени и возможностью вовлечения необходимого для успеха мероприятия круга участников.

2. Классификация механизмов общественного участия.

Комплекс механизмов общественного участия исследователи разделяют на три большие группы в соответствии с их функциями: информационные, консультационные и механизмы по совместной разработке и реализации стратегических документов. Данная классификация позволяет характеризовать различные механизмы общественного участия с позиций интенсивности обратных связей и качества общественного участия в соответствии с моделью «лестницы» Шерри Арнштейн [Arnstein, 1969]. Только третий вид механизмов имеет характер взаимодействия и соучастия, обеспечивающий вовлечение сетевых сообществ в процесс стратегирования городов и регионов в качестве реальных стейкхолдеров. Поэтому перечислим именно эти механизмы [Рисин, Шаталова, 2008, с. 4]:

a) использование формализованных институтов общественного участия (тематические, проектные и иные рабочие группы, общественные советы, территориальные институты развития в форме НКО, фонды местного сообщества и др.). Эти механизмы проигрывают остальным в массовости, они наиболее затратны, но их вклад в конечный результат максимален;

б) публичные круглые столы (механизм непосредственного и активного общественного участия, позволяющий «протестировать» общественное мнение);

в) организация иных коммуникационных площадок (дискуссионных, переговорных и др.), проведение форумов, использование различных формализованных институтов общественного участия (общественных палат и др.), обеспечивающих минимизацию ресурсных затрат при организации диалога;

г) общественные экспертизы и различные формы мониторинга процессов реализации стратегий и программ развития территории; д) собрания / конференции и сходы граждан (целесообразно только для небольших по размеру муниципальных образований);

e) «жюри граждан» (Citizens Jury) [Crosby, Hottinger, 2011] - один из наиболее известных в мировой практике методов публичных консультаций, который появился в середине 1970-х гг. практически одновременно в США, где его развивали Нед Кросби и его коллеги по Центру Джефферсона (http://www.jefferson-center.org), и Германии, где он назывался «ячейками планирования»;

ж) краудсорсинговые и краудфандинговые платформы (поиск идеи и источников софинансирования).

Каждый из перечисленных выше механизмов обладает своими преимуществами. И если в каждый конкретный момент, как правило, приходится выбирать какой-то один из них, то в ходе реализации «стратегического цикла» их можно сочетать, используя на разных фазах цикла в зависимости от характера решаемых задач.

\section{Инструменты цифровизации для организации коммуникации и совместной работы с сетевыми сообществами в процессе стратегирования городов и регионов: новые возможности и риски «технократизма»}

Завершая работу, нельзя не коснуться глобального тренда «цифровизации» экономики и общества, который пересекается и взаимодействует с трендом их «сетевизации». Иногда в связи с этим даже говорят о процессе «цифровой трансформации мира». Действительно, «цифровизация» значительно упрощает распространение сетевых связей и отношений, однако при этом можно предположить, что сама по себе «цифровизация» без преобразования мира на основе сетевой организации ни к какой «трансформации» не приводит. Напротив, происходит лишь «оцифровка» существующих общественных отношений, в результате которой передовая технологическая форма лишь прикрывает морально устаревшее содержание.

Поэтому в нашей предыдущей работе [Красникова, Марача, 2018, с. 106] был сделан вывод, что сами по себе цифровые технологии не решают накопившихся проблем, приводящих к низкому качеству работы институтов общественного участия в процессе стратегирования 
в России. Более того, доминирование «технократического» подхода порождает риск консервации устаревших моделей управления и архаичных институтов. При этом было отмечено, что цифровые технологии и использование Интернета открывают новые каналы и возможности для горизонтального взаимодействия государственной власти и стейкхолдеров в процессе стратегирования, делают это взаимодействие проще и доступнее. Кроме привычного для России использования цифровых технологий при проведении интернет-опросов, новые технологические возможности могут быть использованы для перехода к партнерской модели коммуникации с локальными (территориальными) сообществами, а также для задействования механизма краудсорсинга (что позволяет вовлекать сообщества экстерриториальные).

Цифровые технологии позволяют создать коммуникационные площадки для организации горизонтального взаимодействия людей на территории, способствуя образованию сетевых сообществ, что дает возможность в процессе стратегирования работать уже не с мнениями отдельных людей, а с сетевыми сообществами, имеющими опыт обсуждения предлагаемых идей и позиций на различных онлайн-форумах и иных коммуникативных площадках, модерируемых с применением цифровых технологий. Таким образом, цифровые технологии действительно способствуют формированию сетевых сообществ и вовлечению их в процесс стратегирования, правда, при условии перехода к партнерской модели коммуникации, а не при «оцифровке» существующих архаичных подходов и институтов, не позволяющих России стать развивающейся страной в подлинном смысле этого понятия.

\section{Заключение}

Роль сетевых сообществ в стратегическом развитии городов и регионов существенно зависит от их вовлеченности в процесс стратегирования и от того, как построен сам этот процесс, на какую модель государственного или муниципального управления он опирается. Анализ лучшего мирового и российского опыта свидетельствует, что наиболее устойчивые позитивные эффекты достигаются при переходе к общественно-сетевой модели New Governance. При этом «для танго нужны двое»: к подобному вовлечению общественности и общественно-сетевому участию должны быть готовы как органы власти, так и сетевые сообще- ства. А это, в свою очередь, зависит от доверия сторон друг к другу, от их способности поддерживать диалоговую модель обсуждения общих проблем, основанную на равноправной «горизонтальной» коммуникации, на отказе от статусной иерархии и начальственного диктата.

Сказанное можно проиллюстрировать на примере конкурса муниципальных стратегий, финал которого прошел 22 октября 2018 г. в рамках XVII Общероссийского форума «Стратегическое планирование в регионах и городах России». Поскольку в финал вышли шесть наиболее достойных стратегий, то практически по всем критериям у них ситуация была более-менее вровень. И решающим критерием (два первых места вырвались вперед именно по этому критерию) стала открытость процесса разработки стратегии и способность вовлечь в процесс разработки и реализации стратегии общественность и стейкходеров.

При этом необходимо обратить внимание, что, когда мы отвечаем на вопрос о технологиях подобного вовлечения, большую роль играет взаимодействие с профессиональными сообществами. То есть речь идет не только о каком-то стандартном «взаимодействии с общественностью», наподобие встреч с жителями или отчетных мероприятий, а именно о профессиональных сообществах. И при этом сама команда муниципальной администрации тоже воспринимает себя как таких же креативных профессионалов. Но тогда, соответственно, они уже с общественностью говорят не как власть с подданными, а как профессионалы с профессионалами.

\section{ПРИМЕЧАНИЯ}

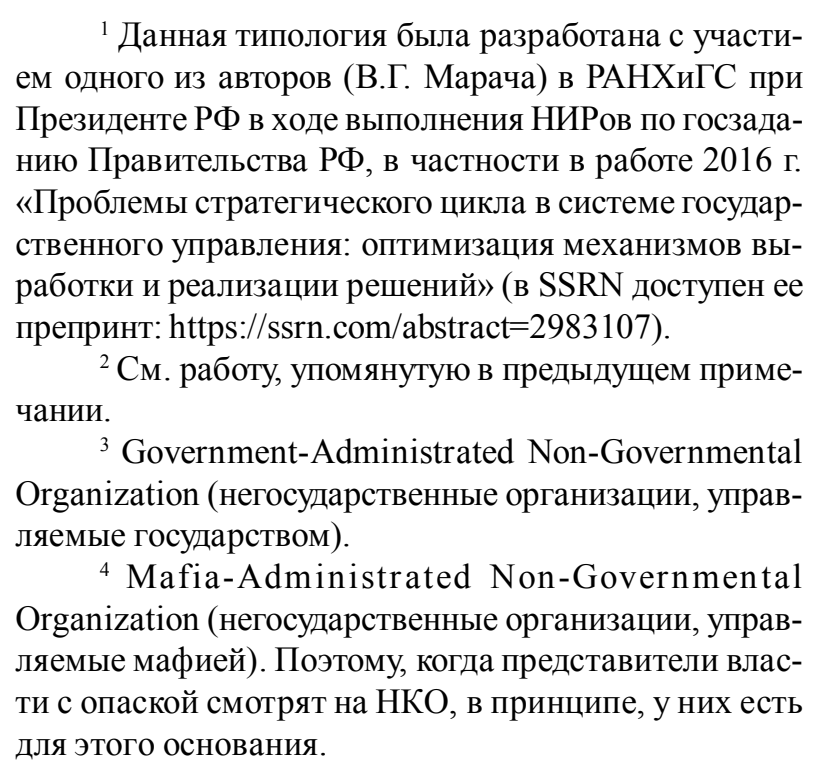




\section{СПИСОК ЛИТЕРАТУРЫ}

Бевир М., 2015. Управление: очень краткое введение. М. : Дело. 160 с.

Казакова М. В., Поспелова Е. А., 2014. Принципы реформ государственного управления в странах ОЭСР // Государственная служба. № 6(92). С. 100104.

Кастельс М., 2000. Информационная эпоха: экономика, общество и культура : пер. с англ. / под науч. ред. О. И. Шкаратана. М. : Изд-во ГУ ВШЭ. 608 с.

Красникова Т. С., Марача В. Г., 2018. Проблемы вовлечения общественности в процесс стратегирования в России: являются ли цифровые технологии выходом? // Региональная экономика. Юг России. № 1 (19). С. 101-109. DOI: https://doi.org/ 10.15688/re.volsu.2018.1.9.

Марача В. Г., 2008. Региональное стратегическое планирование: основные подходы и условия реализации // Проблемы теории и практики управления. № 11. С. 35-42.

Марача В. Г., Красникова Т. С., 2017. Эволюция форм организации инновационного процесса: переход к коллаборативным сетям и «кластерная организация управления» // Управление развитием крупномасштабных систем (MLSD’2017). В 2 т. Т. 2. Секции 7-13 : тр. Десятой междунар. конф., 24 окт. 2017 г., г. Москва / под общ. ред. С. Н. Васильева, А. Д. Цвиркуна. М. : ИПУ РАН. С. 376-383.

Рисин И. Е., Шаталова Е. А., 2008. Инновации в системе стратегического планирования социально-экономического развития городов: зарубежный опыт // Инновационное развитие регионов. № 1. С. 4-7.

Смородинская Н. В., 2014. Сетевые инновационные экосистемы и их роль в динамизации экономического роста // Инновации. № 7 (189). С. 27-33.

Социокультурные факторы инновационного развития и успешной имплементации реформ : докл. ЦСР, 2017. М. : [б. и.] URL: http://csr.ru/wp-content/ uploads/2017/09/Report-SF.pdf.

Федеральный закон от 28.06.2014 № 172-Ф3 О стратегическом планировании в Российской Федерации. Доступ из справ.-правовой системы «КонсультантПлюс».

Arnstein S. R., 1969. A Ladder of Citizen Participation // JAIP. Vol. 35, №4. P. 216-224. URL: http://lithgowschmidt.dk/sherry-arnstein/ladder-of-citizenparticipation.html.

Bramwell A., Hepburn N., Wolfe D. A., 2012. Growing Innovation Ecosystems: University-Industry Knowledge Transfer and Regional Economic Development in Canada. Final Report. Toronto: University of Toronto. $62 \mathrm{p}$.

Breznik K., 2016. Using Social Network Analysis to Identify Innovation Clusters // International Journal of Innovation and Learning. № 19 (3). P. 272-285.

Camarinha-Matos L. M., Afsarmanesh H., 2008. Classes of Collaborative Networks // Encyclopedia of
Networked and Virtual Organizations / ed. by G. D. Putnik, M. M. Cruz-Cunha. Hershey (PA) : IGI Global. P. 193-198.

Crosby N., Hottinger J. C., 2011. Citizens Jury Process // Book of the States. URL: http://knowledgecenter.csg.org/kc/ content/citizens-jury-process.

Desrochers P., 2001. Geographical Proximity and the Transmission of Tacit Knowledge // The Review of Austrian Economics. № 14:1. P. 25-46.

Farrŭ-Perdiguer M., Sala-Rios M., Torres-Solй T., 2016. Network Analysis for the Study of Technological Collaboration in Spaces for Innovation. Science and Technology Parks and their Relationship with the University // International Journal of Educational Technology in Higher Education. № 13:8. URL: https://link.springer.com/article/10.1186/s41239-0160012-3.

Gilsing V., 2000. Cluster Governance: How Clusters Can Adapt and Renew over Time // DRUID PhDconference, Copenhagen, Jan. 2000. P. 18-27.

Gloor P. A., 2006. Swarm Creativity: Competitive Advantage through Collaborative Innovation Networks. N. Y. : Oxford University Press. 212 p.

Hartay E., 2011. Citizen Participation. Best Practices in the Western Balkans and the European Union. URL: http://www.kcsfoundation.org/repository/docs/ 03_03_2014_3974014_KCSF_2011_Best_practices on_Citizen_Participation_in_WB_and_EU.pdf.

He B. H., 2016. The Features and Evolution of Cluster Supply Chain Network // Open Journal of Business and Management. № 4. P. 751-762.

Jackson M., 2003. Systems Thinking: Creative Holism for Managers. Chichester, UK : John Wiley \& Sons. $352 \mathrm{p}$.

Kemeny T., Feldman M., Ethridge F., Zoller T., 2016. The Economic Value of Local Social Networks // J. Econ. Geogr. № 16 (5). P. 1101-1122.

King Ch. S., Stivers C., 1998. Government is Us: Public Administration in an Anti-Government Era. Thousand Oaks (CA) : Sage. 223 p.

Nelson N., Wright S., 1995. Power and Participatory Development: Theory and Practice. L. : Intermediate Technology Publications. $225 \mathrm{p}$.

Nieto M. J., SantamarHa L., 2007. The Importance of Diverse Collaborative Networks for the Novelty of Product Innovation // Technovation. № 27 (6-7). P. 367-377.

Oldfield A., 1990. Citizenship and Community: Civic Republicanism and the Modern World. L. : Routledge. 208 p.

Porter M., 1998. Clusters and the New Economics of Competition // Harvard Business Review. Nov.-Dec. P. 77-90.

Smorodinskaya N., Russell M. G., Katukov D., Still K., 2017. Innovation Ecosystems vs. Innovation Systems in Terms of Collaboration and Co-creation of Value // Proceedings of the 50th Hawaii International Conference on System Sciences, 2017. P. 5245-5254. 
URL: https://inecon.org/docs/2018/Smorodinskaya_ Katukov_paper_HICCS_2017.pdf.

Standards of Public Participation. Recommendations for Good Practice (2008; adopted by the Austrian Council of Ministers on 2 July 2008), 2008. URL: https://www.unece.org/fileadmin/DAM/env/pp/ ppeg/Austria_pp_standards.pdf.

Thomson A. M., Perry J. L., 2006. Collaboration Processes: Inside the Black Box // Public Administration Review. Vol. 66. P. 20-32.

Turkina E., van Assche A., Kali R., 2016. Structure and Evolution of Global Cluster Networks: Evidence from the Aerospace Industry // J. Econ. Geogr. № 16 (6). P. 1211-1234.

Van den Berg L., Braun E., van Winden W., 2001. Growth Clusters in European Cities: An Integral Approach // Urban Studies. Vol. 38, № 1. P. 185-205.

Weber M., 2015. Bureaucracy// Weber's Rationalism and Modern Society: New Translations on Politics, Bureaucracy, and Social Stratification / ed. and transl. by T. Waters, D. Waters. N. Y. : Palgrave MacMillan. P. 73-127.

Wilson W., 1887. The Study of Administration // Political Science Quarterly. Vol. 2, № 2 (June). P. 197-222.

\section{REFERENCES}

Bevir M., 2015. Upravlenie: ochen kratkoe vvedenie [Governance: A Very Short Introduction]. Moscow, Delo Publ. 160 p.

Kazakova M.V., Pospelova E.A., 2014. Printsipy reform gosudarstvennogo upravleniya $\mathrm{v}$ stranakh OESR [Principles of Public Administration Reforms in OECD Countries]. Gosudarstvennaia sluzhba, no. 6 (92), pp. $100-104$.

Castells M., 2000. Informatsionnaya epoha: ekonomika, obshchestvo $i$ kultura [The Information Age: Economy, Society and Culture]. Moscow, State University Higher School of Economics Publ. 608 p.

Krasnikova T.S., Maracha V.G., 2018. Problemy vovlecheniya obshchestvennosti $\mathrm{v}$ protsess strategirovaniya v Rossii: yavlyayutsya li tsifrovye tekhnologii vykhodom? [Problems of Public Involvement in Strategic Planning Process in Russia: Whether Digital Technologies Are a Decision?]. Regionalnaya ekonomika. Yug Rossii [Regional Economy. The South of Russia], no.1, pp. 101-109. DOI: https://doi.org/10.15688/re.volsu.2018.1.9.

Maracha V.G., 2008. Regionalnoe strategicheskoe planirovanie: osnovnye podkhody i usloviya realizatsii [Regional Strategic Planning: the Basic Approaches and Conditions of Implementation]. Problemy teorii $i$ praktiki upravleniya, no. 11, pp. 35-42.

Maracha V.G., Krasnikova T.S., 2017. Evolyutsiya form organizatsii innovatsionnogo protsessa: perekhod $\mathrm{k}$ kollaborativnym setyam i «klasternaya organizatsiya upravleniya» [The Evolution of Innovation Process
Organization Forms: Transfer to Collaboration Networks and "Cluster Governance"]. Upravlenie razvitiem krupnomasshtabnyh sistem (MLSD'2017).V2 t. T. 2. Sektsiya 7-13: tr. Desyatoy mezhdunar. conf., 2-4 okt. 2017, g. Moskva [Management of Large-scale System Development (MLSD'2017). In 2 vols. Vol. 2. Sections 7-13: Proceedings of $10^{\text {th }}$ International Conference, 2-4 Oct. 2017, Moscow]. Moscow, Institute of Management Problems RAS Publ., pp. 376-383.

Risin I.E., Shatalova E.A., 2008. Innovatsii v sisteme strategicheskogo planirovaniya sotsialnoekonomicheskogo razvitiya gorodov: zarubezhnyy opyt [Innovations in the System of Strategic Planning of Cities' Socio-Economic Development: International Experience]. Innovatsionnoe razvitie regionov, no. 1, pp. 4-7.

Smorodinskaya N.V., 2014. Setevye innovatsionnye ekosistemyi ikh rol v dinamizatsii ekonomicheskogo rosta [Network Innovation Ecosystems and Their Role in Dynamisation of Economic Growth]. Innovatsii, no. 7 (189), pp. 27-33.

Sotsiokulturnye faktory innovatsionnogo razvitiya $i$ uspeshnoy implementatsii reform: dokl. CSR, 2017 [Socio-Cultural Factors of Innovative Development and Successful Implementation of Reforms: Report of the CSR]. Moscow. URL: http://csr.ru/wp-content/ uploads/2017/09/Report-SF.pdf.

Federalnyy zakon ot 28.06.2014 № 172-FZ "O strategicheskom planirovanii v Rossiyskoy Federatsii» [On Strategic Planning in the Russian Federation: Federal Law of June 28, 2014 No. 172-FZ]. Access from Reference Legal System "KonsultantPlus".

Arnstein S.R., 1969. A Ladder of Citizen Participation. JAIP, vol. 35 , no. 4, pp. 216-224. URL: http://lithgowschmidt.dk/sherry-arnstein/ladder-of-citizenparticipation.html.

Bramwell A., Hepburn N., Wolfe D.A., 2012. Growing Innovation Ecosystems: University-Industry Knowledge Transfer and Regional Economic Development in Canada.Final Report. Toronto, University of Toronto. $62 \mathrm{p}$.

Breznik K., 2016. Using Social Network Analysis to Identify Innovation Clusters. International Journal of Innovation and Learning, no. 19 (3), pp. 272-285.

Camarinha-Matos L.M., Afsarmanesh H., 2008. Classes of Collaborative Networks. Putnik G.D., CruzCunha M.M., eds. Encyclopedia of Networked and Virtual Organizations. Hershey (PA), IGI Global, pp. 193-198.

Crosby N., Hottinger J.C., 2011. Citizens Jury Process. Book of the States. URL: http://knowledgecenter.csg.org/ $\mathrm{kc} /$ content/citizens-jury-process.

Desrochers P., 2001. Geographical Proximity and the Transmission of Tacit Knowledge. The Review of Austrian Economics, no. 14:1, pp. 25-46. 
Farré-Perdiguer M., Sala-Rios M., Torres-Solé T., 2016. Network Analysis for the Study of Technological Collaboration in Spaces for Innovation. Science and Technology Parks and their Relationship with the University. International Journal of Educational Technology in Higher Education, no. 13:8. URL: https:/ /link.springer.com/article/10.1186/s41239-016-0012-3.

Gilsing V., 2000. Cluster Governance: How Clusters Can Adapt and Renew over Time. DRUID PhDconference.Copenhagen, Jan. 2000, pp.18-27.

Gloor P.A., 2006. Swarm Creativity: Competitive Advantage through Collaborative Innovation Networks. New York, Oxford University Press. 212 p.

Hartay E., 2011. Citizen Participation. Best Practices in the Western Balkans and the European. URL: http:// www.kcsfoundation.org/repository/docs/03_03 2014_3974014_KCSF_2011_Best_practices_on_ Citizen_Participation_in_WB_and_EU.pdf.

He B.H., 2016. The Features and Evolution of Cluster Supply Chain Network. Open Journal of Business and Management, no. 4, pp. 751-762.

Jackson M., 2003. Systems Thinking: Creative Holism for Managers. UK, Chichester, John Wiley \& Sons. 352 p.

Kemeny T., Feldman M., Ethridge F., Zoller T., 2016. The Economic Value of Local Social Networks. J. Econ. Geogr., no. 16(5), pp. 1101-1122.

King Ch.S., Stivers C., 1998. Government is Us: Public Administration in an Anti-Government Era. Thousand Oaks (CA), Sage. 223 p.

Nelson N., Wright S., 1995. Power and Participatory Development: Theory and Practice. London, Intermediate Technology Publications. $225 \mathrm{p}$.

Nieto M.J., SantamarHa L., 2007. The Importance of Diverse Collaborative Networks for the Novelty of Product Innovation. Technovation, no. 27 (6-7), pp. 367-377.
Oldfield A., 1990. Citizenship and Community: Civic Republicanism and the Modern World. London, Routledge. 208 p.

Porter M., 1998. Clusters and the New Economics of Competition. Harvard Business Review, Nov.-Dec., pp. 77-90.

Smorodinskaya N., Russell M.G., Katukov D., Still K., 2017. Innovation Ecosystems vs. Innovation Systems in Terms of Collaboration and Co-creation of Value. Proceedings of the $50^{\text {th }}$ Hawaii International Conference on System Sciences, pp. 5245-5254. URL: https://inecon.org/docs/2018/Smorodinskaya_ Katukov_paper_HICCS_2017.pdf.

Standards of Public Participation. Recommendations for Good Practice (adopted by the Austrian Council of Ministers on 2 July 2008), 2008. URL: https:// www.unece.org/fileadmin/DAM/env/pp/ppeg/ Austria_pp_standards.pdf.

Thomson A.M., Perry J.L., 2006. Collaboration Processes: Inside the Black Box. Public Administration Review, vol. 66, pp. 20-32.

Turkina E., van Assche A., Kali R., 2016. Structure and Evolution of Global Cluster Networks: Evidence from the Aerospace Industry. J. Econ. Geogr, no. 16 (6), pp. 1211-1234.

Van den Berg L., Braun E., van Winden W., 2001. Growth Clusters in European Cities: An Integral Approach. Urban Studies, vol. 38, no. 1, pp. 185-205.

Weber M. Bureaucracy, 2015. Waters T., Waters D., eds. Weber's Rationalism and Modern Society: New Translations on Politics, Bureaucracy, and Social Stratification. NewYork, Palgrave MacMillan, pp. 73-127.

Wilson W., 1887. The Study of Administration. Political Science Quarterly, vol. 2, no. 2 (June), pp. 197-222.

\section{Information about the Authors}

Vyacheslav G. Maracha, Candidate of Sciences (Philosophy), Leading Researcher, Russian Presidential Academy of National Economy and Public Administration, Prosp. Vernadskogo, 82, bld. 1, 119571 Moscow, Russian Federation; Associate Professor of Department of Systemic Analysis in Economics, Financial University under the Government of the Russian Federation, Prosp. Leningradsky, 49, 125993 Moscow, Russian Federation, maratcha@yandex.ru, https://orcid.org/0000-0002-4556-3363

Tatyana S. Krasnikova, Candidate of Sciences (Economics), Executive Director, Scientific Research LLC, Aviamotornaya St., 50/2, 111024 Moscow, Russian Federation, info@nrzr.ru, https://orcid.org/0000-0001-7623-5357

\section{Информация об авторах}

Вячеслав Геннадиевич Марача, кандидат философских наук, ведущий научный сотрудник, Российская академия народного хозяйства и государственной службы при Президенте РФ, просп. Вернадского, 82, стр. 1, 119571 г. Москва, Российская Федерация; доцент кафедры системного анализа в экономике, Финансовый университет при Правительстве РФ, просп. Ленинградский, 49, 125993 г. Москва, Российская Федерация, maratcha@yandex.ru, https://orcid.org/0000-0002-4556-3363

Татьяна Сергеевна Красникова, кандидат экономических наук, исполнительный директор, ООО «Научные разработки», ул. Авиамоторная, 50/2, 111024 г. Москва, Российская Федерация, info@nrzr.ru, https://orcid.org/0000-0001-7623-5357 